\title{
ARqueObotánICA dEL SITIO TEMPRANo SORIA 2 (Catamarca, Argentina)
}

\author{
Archaeobotany of the early site Soria 2 (Catamarca, Argentina)
}

1. Laboratorio de Etnobotánica y Botánica Aplicada, Facultad de Ciencias Naturales y Museo, U.N.L.P.

2. Centro Regional de Investigaciones Científicas y Transferencia Tecnológica de La Rioja (CRILAR) - CONICET.

*nataliapetrucci@gmail.com

\section{Citar este artículo}

PETRUCCI, N. \& R. SPANO. 2019. Arqueobotánica del sitio temprano Soria 2 (Catamarca, Argentina). Bol. Soc. Argent. Bot. 54: 137-154.

DOI: http://dx.doi. org/10.31055/1851.2372.v54. n1.23591

Recibido: 17 Octubre 2018 Aceptado: 6 Diciembre 2018 Publicado: 28 Marzo 2019 Editora: Norma Hilgert

\section{Natalia Petrucci ${ }^{1 *}$ iD y Romina Spano ${ }^{2}$ (iD}

\section{SUMMARY}

Background and aims: In the valley of Santa María or Yocavil the archeobotanical studies included the systematic recovery of remains by means of the flotation technique. However, plant archaeological remains have been scarcely studied so far. The aim of this paper is to present the identification of plant remains recovered by flotation and contribute to the interpretation, in this case, the site early Soria 2 located in the Valley, from analysis of this research.

M\&M: The flotation technique implemented was mechanical. Quantification methods used were: absolute amount, relative frequency, density and ubiquity. Once identified, the taxa were analyzed according to modes of association with human communities: wild, weedy and domesticated.

Results: The following taxa could be taxonomically identified: Trichocereus sp., Geoffroea decorticans, Chenopodium sp., Opuntia sp., Prosopis spp., Zea mays and Solanaceae. When grouping the taxa according to their degree of association we see that the ruderal weeds are the ones with the highest densities, followed by the wild ones, while the rest presented similar density percentages.

Conclusions: The differences of presence / absence of taxa and proportions between the different spaces that make up the domestic unit, could indicate differential activities carried out in the past, suggesting practices with different spatial anchorage. The carpological set of the site suggests the presence and the use of disturbed and undisturbed environments next to cultivation spaces indicated by domesticated plants and agricultural weeds for early moments.

\section{KEY WORDS}

Valley of Santa María, archaeobotany, flotation, identification, modes of association.

\section{RESUMEN}

Introducción y objetivos: En el valle de Santa María o Yocavil los estudios arqueobotánicos comprendieron la recuperación sistemática de restos mediante la técnica de flotación. No obstante los restos arqueológicos vegetales han sido escasamente estudiados hasta el momento. El objetivo de este trabajo es presentar la identificación de los restos vegetales recuperados por flotación y contribuir a la interpretación, en este caso, del sitio temprano Soria 2, emplazado en el Valle, a partir de análisis de esta línea de investigación.

M\&M: La técnica de flotación implementada fue de tipo mecánica. Los métodos de cuantificación utilizados fueron: cantidad absoluta, frecuencia relativa, densidad y ubicuidad. Una vez identificados, los taxa se analizaron de acuerdo a modos de asociación con comunidades humanas: silvestre, maleza y domesticado.

Resultados: Se pudieron identificar taxonómicamente los siguientes taxa: Trichocereus sp., Geoffroea decorticans, Chenopodium sp., Opuntia sp., Prosopis spp., Zea mays y Solanaceae. Al agrupar los taxa según su grado de asociación vemos que las malezas ruderales son las que mayores densidades presentaron, seguidas por las silvestres, en tanto que el resto presentó porcentajes de densidad similares.

Conclusiones: Las diferencias de presencia/ausencia de taxa y de proporciones entre los distintos espacios que componen la unidad doméstica, podrían indicar actividades diferenciales efectuadas en el pasado, sugiriendo prácticas con diferente anclaje espacial. El conjunto carpológico del sitio nos sugiere la presencia y el aprovechamiento de ambientes disturbados y no disturbados junto a espacios de cultivo indicados por plantas domesticadas y malezas agrícolas para momentos tempranos.

\section{Palabras clave}

Valle de Santa María, arqueobotánica, flotación, identificación, modos de asociación. 


\section{INTRODUCCIÓN}

Las investigaciones enmarcadas en la interdisciplina arqueobotánica han aumentado hace poco más de dos décadas en nuestro país. La misma es entendida como las interrelaciones entre los seres humanos y las plantas en el pasado, a partir del estudio de macro y microrrestos presentes en los sitios arqueológicos. En el valle de Santa María o Yocavil los estudios de esta índole comprendieron la recuperación sistemática de restos arqueobotánicos mediante la técnica de flotación, cuyo resultado fue la colecta de un importante corpus de materiales a lo largo del tiempo. No obstante, por variadas circunstancias, los restos arqueológicos vegetales han sido escasamente estudiados hasta el momento. El objetivo de este trabajo es presentar la identificación de los restos vegetales recuperados por flotación y contribuir a la interpretación, en este caso, del sitio temprano Soria 2 (período comprendido, aproximadamente, entre el $600 \mathrm{AC}$ y el $600 \mathrm{AD}$ ), emplazado en el Valle, a partir de análisis de esta línea de investigación.

El sitio Soria 2 (Fig. 1), se localiza entre las sierras del Aconquija y el sector sudoriental del valle de Santa María; se asienta en una antigua terraza del tercer nivel pedemontano (mesada de Andalhuala Banda, MAB) de la formación Caspinchango, sobre cuyo sector sur se ubica el poblado actual de Andalhuala Banda (Spano et al., 2014a).

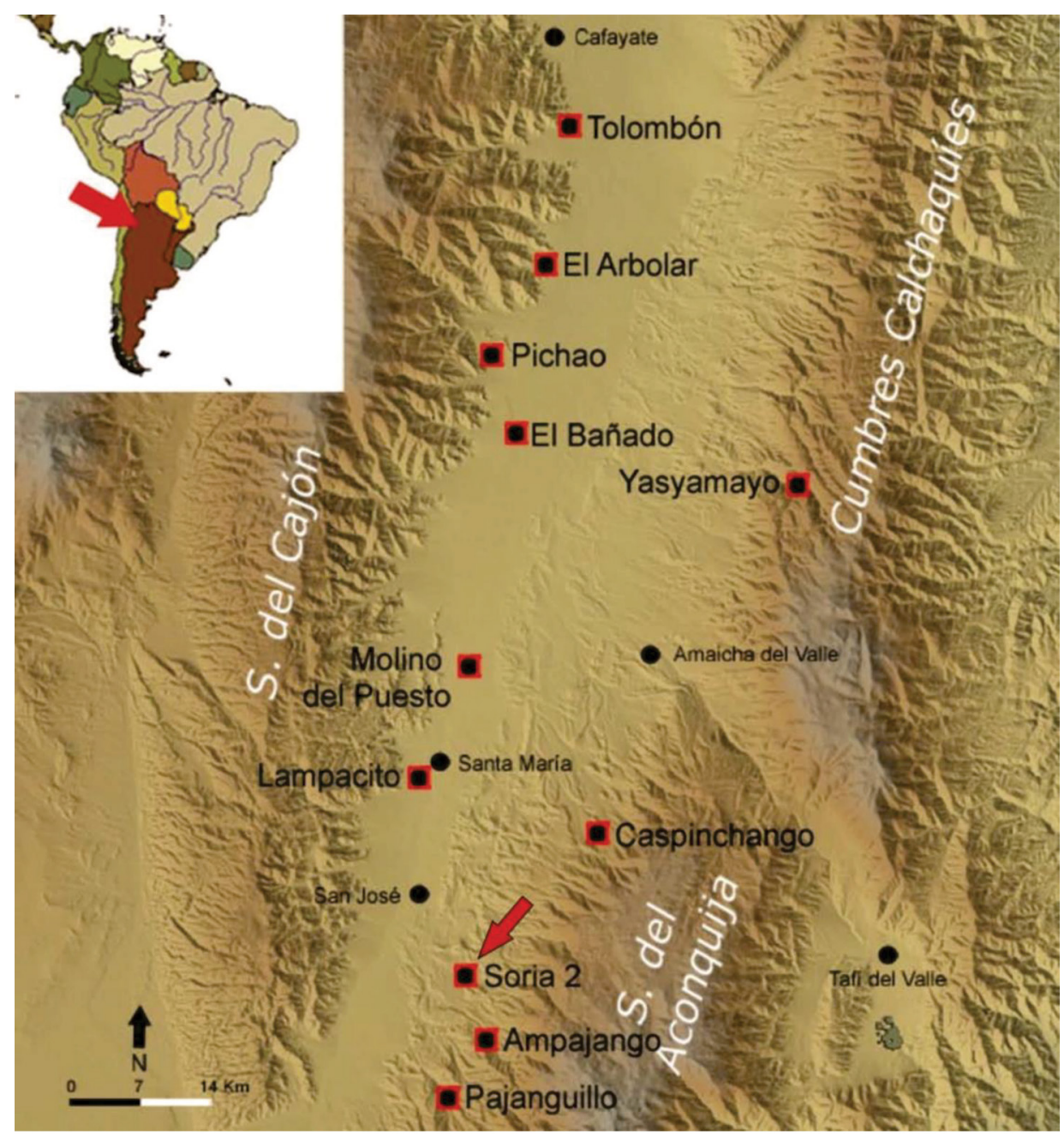

Fig. 1. Ubicación del sitio Soria 2 y otros sitios tempranos en el valle de Santa María (tomado de Spano, 2011). 


\section{N. Petrucci y R. Spano - Arqueobotánica del sitio temprano Soria 2}

La flora local se corresponde con la estepa de Larrea o de jarillas -arbustal abierto con ejemplares que no superan el 1,50 m de alto, compuesto principalmente por Larrea cuneifolia, Larrea divaricata y $L$. nítida- y con el monte espinoso -arbustal abierto con predominio de especies caducifolias espinosas(Morlans, 1995), ambos pertenecientes a la provincia de Monte (Cabrera, 1976). También se encuentra presente la provincia Pre-puneña caracterizada por cactáceas columnares de gran tamaño (Morlans, 1995).

La evidencia arquitectónica y los estilos alfareros de superficie indican una ocupación que abarcaría, al menos, desde tiempos tempranos hasta la actualidad. En algún momento de ese período, el lugar presentó una fisonomía de aldea, posiblemente respondiendo a un sistema de asentamiento con unidades domésticas de residencia familiar, dispersas en campos agrícolas, implicando un área de al menos 70 ha de extensión (Álvarez Larrain, 2009, 2014). La sostenida ocupación en el tiempo de la mesada dificulta determinar la extensión del espacio destinado a trabajos agrícolas en tiempos tempranos, ya que existe superposición de estructuras arquitectónicas a lo largo de más de 1500 años. La excavación del conjunto arquitectónico de Soria 2 permitió identificar una unidad compuesta por, al menos, dos recintos subcuadrangulares adosados, denominados 1 y 2 , que constituyó una casa; el patio ( $\mathrm{R} 1$, en adelante), construido con posterioridad al recinto 2 (R2), data de inicios de la Era (1940 + 80 AP, 103 AC-310 DC cal); en ambos recintos se hallaron entierros de infantes, depositados luego del abandono de la casa (Palamarczuk et al., 2007, Spano et al., 2014a, b) (Fig. 2). La parte superior del piso de ocupación del conjunto arquitectónico se halló a una profundidad variable entre 20 y $45 \mathrm{~cm}$ por debajo de la superficie actual del terreno, la cual presenta una pendiente hacia el oeste (Palamarczuk et al., 2007). Al noroeste del R1 se dispone adosada otra estructura arquitectónica (E3), la cual no fue intervenida mediante excavación en área hasta el momento; solo es posible observar una línea de piedras dispuestas en sentido norte-sur, descubierta mediante una limpieza expeditiva.

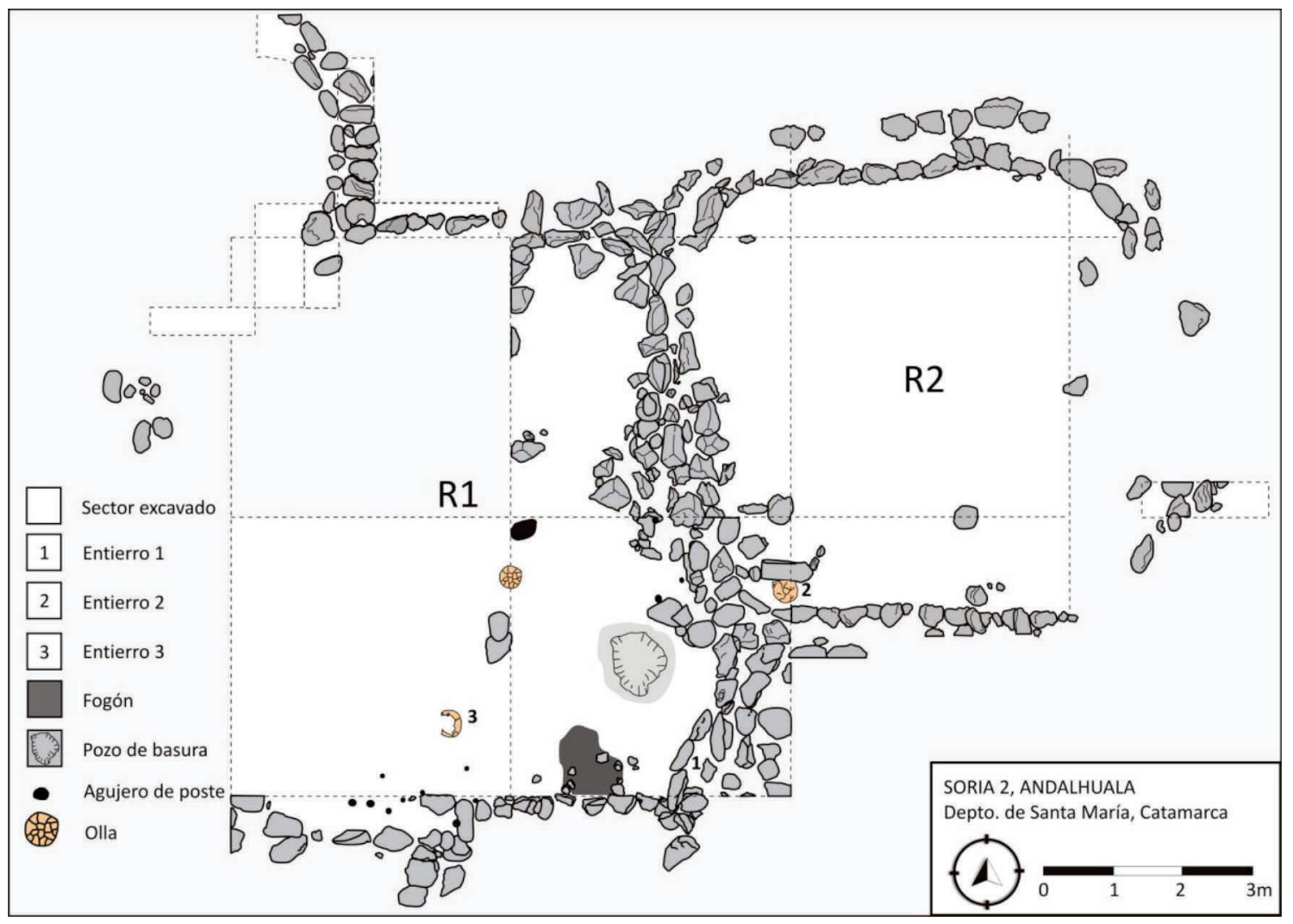

Fig. 2. Planta del sitio Soria 2 con indicación de áreas excavadas (tomado de Álvarez Larrain, 2014). 
La excavación se ordenó mediante el trazado de cuadrículas de 4 por 4 metros; se efectuó decapado siguiendo el método estratigráfico (Harris, 1991). De este modo, se identificaron unidades estratigráficas de procedencia para referenciar los hallazgos e interpretar los procesos de formación del sitio. Durante la excavación se separaron muestras para aplicar la técnica de flotación sobre los sedimentos con el propósito de recuperar restos arqueobotánicos. Ésta tiene como finalidad recuperar aquellos elementos que, por su reducido tamaño, usualmente no son detectados durante el proceso de excavación por decapado ni en la zaranda seca de malla fina, sin sufrir deterioro.

\section{Los recintos}

La excavación del recinto R1 permitió definir un piso de ocupación y rasgos, como agujeros de poste alineados que pudieron sostener algún tipo de techado o enramada. En la zona sureste del recinto se detectó un fogón contenido por un semicírculo de piedras tiznadas y termoalteradas (Palamarczuk et al., 2007). Un fechado radiocarbónico convencional obtenido sobre carbón de dicho fogón resultó en $1940 \pm 80$ años A.P. (L.P. 1541) (Palamarczuk et al., 2007). Además, se recuperaron 3.877 especímenes $(\mathrm{NISP}=766)$ de restos óseos faunísticos, la mayor parte de camélidos (Belotti, 2011); 996 artefactos líticos, principalmente de andesita, incluyendo desechos, núcleos, dos puntas de proyectil de obsidiana y otros instrumentos como artefactos de molienda simples (Carbonelli, 2009, 2011); y 8.707 fragmentos de cerámica, con un $25 \%$ de cerámica fina, fundamentalmente de cocción en atmósfera pobre en oxígeno y superficie pulida y un $75 \%$ de cerámica ordinaria, de cocción oxidante y superficies mayormente alisadas (Spano, 2011); estos hallazgos se encontraron asociados al piso de ocupación. Al norte del fogón, aproximadamente a $1 \mathrm{~m}$, se localizó un pozo de residuos. El mismo es un rasgo de planta pentagonal de $21,5 \mathrm{~cm}$ de profundidad, lleno de sedimento carbonoso, fragmentos cerámicos artefactos líticos, huesos de fauna y semillas quemadas (Spano, 2008). También se encontró una inhumación secundaria de al menos dos individuos, un niño y un infante, con un fechado obtenido por AMS de 1730 \pm 46 AP (AA87351) (Spano et al., 2014 a: 8-9). En este espacio se dispuso también el entierro primario de un neonato en olla, fechado por AMS en 1766 \pm 46 AP (AA87353) (Spano et al., 2014a).
En el recinto R2 se encontró un entierro primario de un neonato en olla, datado por AMS $1762 \pm 46$ AP (AA87352) (Spano et al., 2014a).

Todos los entierros fueron llevados a cabo post abandono (Spano et al., 2014a).

De la excavación las tres estructuras arquitectónicas se obtuvieron muestras de flotación, en las cuales se pondrá el foco en esta contribución. Las evidencias de uso de plantas en el sitio obtenidas a través de otras vías de análisis, como estudios químicos e inspecciones de microrrestos colectados al interior de artefactos, han sido comunicadas en artículos previos (Rosso \& Spano, 2005-2006; Andreoni et al., 2012), otras se encuentran inéditas por ahora.

\section{Materiales y Métodos}

\section{Técnica de recuperación de los restos arqueobotánicos}

Las muestras de flotación analizadas provienen de baldes de ocho litros de capacidad de sedimento, extraídos al azar a razón de un balde de diez, de cada unidad de procedencia excavada, representando de esta manera un $10 \%$ del total de universo. La técnica de flotación implementada fue de tipo mecánica: se empleó una máquina cuyo efecto agitador lo realizaba una toma de agua corriente conectado a un regador que hacía a su vez el efecto de burbujeo. Se separó el sedimento en fracción liviana $(<5 \mathrm{~mm})$ y pesada $(>5 \mathrm{~mm})$, y se les adjuntó una tarjeta de identificación. La fracción liviana fue tendida en una soga para su secado, mientras que la fracción pesada se dejó secar al descubierto. Una vez seca se embolsó la fracción pesada en bolsas plásticas.

Se tomaron en total 151 muestras, las cuales totalizaron 376 litros en el R1, 440 litros en el R2 y 152 litros en el E3. En el caso de la E3, al estar poco excavado, consideramos que los datos derivados del espacio intervenido no son extrapolables a toda la estructura, de manera que solo se contabilizaron los restos recuperados, pero no se consideraron para el análisis.

Los materiales recuperados en zaranda seca durante los trabajos de excavación se encuentran en proceso de estudio.

\section{Metodología de identificación}

Los tejidos blandos no se conservan en ambientes físicos de depositación, salvo aquellos 


\section{N. Petrucci y R. Spano - Arqueobotánica del sitio temprano Soria 2}

anaeróbicos permanentes o extremadamente secos, si el suelo tiene $\mathrm{pH}$ por debajo de 5.5 (Ford, 1979). Sólo quedan microrrestos, como polen y fitolitos, en el depósito sedimentario. La actividad de microrganismos presentes en el suelo y los procesos geológicos impactan continuamente los depósitos. Estos disturbios son menores en aleros y cuevas, mientras que en sitios a cielo abierto son más activos (Popper, 1988). El tipo de clima semidesértico del valle de Santa María no favorece la preservación de los restos orgánicos, de manera que para asegurarnos que los macrorrestos recuperados pertenecieran a vestigios de las ocupaciones pretéritas del sitio, se consideraron solo los que se encontraban carbonizados. De la diversidad de macrorrestos recuperados se consideraron para este trabajo solo los carporrestos que se encontraron en los niveles asociados al piso de ocupación. La evaluación de procesos tafonómicos se realizó identificando los restos carpológicos en todos los niveles y no solo en los ocupacionales, al igual que los ejemplares secos. Estos últimos podrían llegar a corresponder a ocupaciones pasadas, o ser parte del aporte de plantas actuales del área, sobre todo en el caso de especies silvestres y malezoides. Ante la escasez de estudios tafonómicos en arqueobotánica -y menos a nivel del valle- que nos permitan evaluar la preservación diferencial de restos secos y cómo esto afectaría las interpretaciones derivadas de los mismos, no los hemos considerado en el análisis. De esta manera, de la totalidad de litros de sedimento flotado, se analizaron 2881 en el R1 y 3841 en el R2.

En una primera instancia en el laboratorio se procesaron las fracciones liviana y pesada, las cuales fueron íntegramente observadas bajo microscopio estereoscópico; de esta manera se dividieron los restos antracológicos de los carporrestos. Una vez que todas las muestras fueron separadas se procedió a la identificación de estos últimos. Para llevar a cabo el reconocimiento taxonómico de los restos se utilizó la información del herbario realizado por Cabrera en 1990 y las colecciones de plantas útiles del Laboratorio de Etnobotánica y Botánica Aplicada de la Facultad de Ciencias Naturales y Museo (FCNyM - UNLP). Se confeccionó además un herbario propio del área de estudio, colectando en distintos momentos del año las plantas incluyendo su parte reproductiva y las semillas. El mismo se encuentra depositado en el Laboratorio de Etnobotánica y Botánica Aplicada (LEBA). Se utilizó además material bibliográfico de referencia (Cabrera, 1971, 1976, 1983; Herbario MCNS, 2011), el Catálogo de las Plantas Vasculares del Conosur (IBODA, 2016), textos sobre caracteres diagnósticos (Winton \& Winton, 1932, 1935) y claves de determinación.

La imposibilidad de asignación taxonómica de algunos restos obedeció a que los mismos presentaban un estado de conservación tan malo que no permitía apreciar caracteres básicos necesarios para cualquier tipo de asignación, incluso la más general; no obstante, sí se pudo comprobar que correspondían a restos vegetales. Así, se consideró y denominó a estos restos como "no identificables".

Una vez identificados, los restos de cada muestra fueron separados y puestos en un sobre de aluminio con una etiqueta que especificaba: sitio, unidad de procedencia (es decir, unidad estratigráfica), recinto, número de muestra, fracción (liviana o pesada) $\mathrm{y}$ un número de identificación. En un cuaderno y en una planilla Excel 2010 se volcaron los datos de las etiquetas, la identificación y observaciones particulares de cada muestra. Para el registro de los datos de laboratorio se confeccionó una tabla estandarizada propia, donde se consignaron variables como: unidad de procedencia, recinto, nivel, número de muestra, taxón, órgano (semilla, endocarpo, marlo/cúpula, por ejemplo), integridad (fragmentado, entero) y cantidad. Los datos una vez registrados fueron procesados gráfica y estadísticamente con el programa Excel.

\section{Métodos de cuantificación}

Los métodos de cuantificación utilizados fueron: cantidad absoluta, frecuencia relativa, densidad y ubicuidad.

Cantidad absoluta se refiere al número de ejemplares (enteros o fragmentados) de un determinado taxón por unidad de muestreo o unidad de procedencia, expresado en número entero. $\mathrm{Si}$ bien el conteo absoluto es la forma primaria de contabilizar y presentar los datos siendo además indispensable para calcular otros parámetros, las cantidades pueden reflejar problemas de preservación diferencial, de manera que no se utilizaron con fines comparativos.

La frecuencia o proporción relativa se refieren a la importancia que tiene un taxón con respecto a otro en una misma muestra individual o agregativa, 
ya que permite estandarizar las cantidades absolutas de cada muestra. La ventaja de este esquema de cuantificación es que todos los taxa pueden ser considerados simultáneamente, sin tener en cuenta el volumen inicial de cada muestra. En este caso, para el análisis, hay que tener en cuenta: la cantidad de semillas que produce la planta, la amplitud ecológica, la frecuencia de consumo, la conservación con respecto a otras especies, la parte que es consumible (Buxó, 1997).

La densidad es expresada como la relación entre el volumen de sedimento flotado en una muestra y la cantidad de restos obtenidos. Se puede utilizar la cantidad absoluta o el peso de los restos recuperados. En nuestro caso estandarizamos la densidad como cantidad absoluta de restos recuperados (n) por litro de sedimento flotado (1). No se utilizó la variable peso, ya que algunos restos poseían un peso tan escaso que no se registraba en balanza de precisión digital. Es una medida estandarizada de los datos que permite comparar muestras de diferentes volúmenes y cantidades originales (Miller, 1988; Popper, 1988; Pearsall, 1989).

La ubicuidad o análisis de presencia no tiene en cuenta la cantidad absoluta de un taxón, sino que considera el número de muestras en que un taxón aparece dentro de un grupo de muestras (Popper, 1988).

Asignación de grados de asociación con comunidades humanas y prácticas de manejo

Una vez identificados, los taxa se analizaron de acuerdo a modos de asociación con comunidades humanas: silvestre, maleza y domesticado. Asimismo, siguiendo a Casas (2001), se consideraron distintas prácticas de manejo (tolerancia, fomento, erradicación y protección) que pueden ser consideradas como modos de cultivo sensu lato, en vez de sensu stricto (donde cultivo es igual a siembra), además de prácticas de recolección (Lema, 2009). Siguiendo las definiciones de De Wet \& Harlan (1975: 100), las plantas silvestres son aquellas que crecen naturalmente y no pueden invadir con éxito, de forma permanente, los hábitats disturbados por el ser humano. Además de recolectadas pueden ser cultivadas (en sentido amplio o estricto), pudiendo tener lugar -en ambos casos- modificaciones en la abundancia y frecuencia génica de las poblaciones (Lema, 2009). El término maleza es el que posee más acepciones, pero en este trabajo la definiremos a partir de su comportamiento ecológico siguiendo a De Wet \& Harlan (1975). De esta manera, las malezas son plantas pioneras de sucesiones secundarias, son exitosas en hábitats disturbados por los humanos y no requieren la intervención de éstos para su propagación. Dentro de esta categoría se encuentran las denominadas "ruderales" que son plantas que crecen en lugares donde habita el ser humano entre construcciones, ruinas o escombros, y las "arvenses" que son plantas que crecen entre los cultivos (De Wet \& Harlan, 1975). Las prácticas de manejo en relación a las malezas pueden ser tolerancia, erradicación, cultivo o recolección (Lema, 2009). Las plantas domesticadas requieren cultivo y la continua intervención del ser humano para su reproducción, ya que las mismas perdieron la habilidad de dispersar sus semillas o propágulos vegetativos por medios naturales; por lo tanto lo que diferencia a las malezas de las plantas domesticadas es el grado de dependencia con los humanos (De Wet \& Harlan, 1975; Harlan, 1992). De lo anterior se desprende también el hecho de que malezas y plantas domesticadas pueden compartir los mismos espacios en el caso de aquellas clasificadas como "arvenses" o "malezas agrícolas", por ello restos de las mismas se han usado en trabajos arqueobotánicos extra americanos como indicadores de ecosistemas agrícolas pasados, considerando que la interacción entre cultivo y maleza marca modalidades de manejo agrícolas particulares (Hartmann et al., 2015). Para ello resulta importante poder identificar malezas obligadas versus facultativas, las primeras -siguiendo la propuesta de Zoharyprosperan solo en campos de cultivo y se asocian en algunos casos a ciertas plantas domesticadas; es por ello que resulta esencial además caracterizar la flora malezoide de los conjuntos arqueobotánicos, distinguiendo grupos característicos de restos de malezas versus la aparición esporádica de una sola maleza (Hartmann et al., 2015).

\section{Resultados}

\section{Identificación de los carporrestos recuperados}

En la tabla 1 se presentan las cantidades absolutas de los taxa recuperados en el sitio Soria 2. 


\section{N. Petrucci y R. Spano - Arqueobotánica del sitio temprano Soria 2}

Tabla 1. Cantidades absolutas de carporrestos carbonizados recuperados de las muestras de flotación del sitio Soria 2.

\begin{tabular}{|lc|}
\hline \multicolumn{1}{|c}{ Taxa } & Soria 2 \\
\hline Trichocereus sp. & 132 \\
Prosopis spp. aff. flexuosa/nigra & 4 \\
Prosopis spp. aff. alba/chilensis & 1 \\
Prosopis spp. aff. flexuosa/nigra/alba/chilensis & 1 \\
Zea mays & 12 \\
Opuntia sp. & 4 \\
Chenopodium sp. & 15 \\
Chenopodium quinoa var. quinoa & 8 \\
Chenopodium aff. carnosulum & 13 \\
Geophroea decorticans & 24 \\
Solanaceae & 9 \\
Identificable tipo leguminosa 1 & 1 \\
Identificable tipo leguminosa 2 & 3 \\
No identificable & 24 \\
Total & 251 \\
\hline
\end{tabular}

El la fig. 3 se observan los carporrestos recuperados en el sitio Soria 2, cuyas descripciones permitieron su identificación.

El color natural de las semillas de Trichocereus sp. (A. Berger) Riccob. es negro, con lo cual no es fácil detectar si las mismas están o no carbonizadas, por ello se les realizó un corte transversal a fin de observar si los tejidos internos estaban o no efectivamente carbonizados. En las fig. 4 A, B, C y D se muestran de forma comparativa dos semillas, recuperadas de los niveles de ocupación. En las fig. 4 A y B se observan los tejidos internos secos, de color castaño, y en las fig. $4 \mathrm{C}$ y D se puede apreciar a los mismos carbonizados; solo estos últimos ejemplares fueron considerados en este trabajo. Lo mismo se realizó con las semillas de Portulaca sp. L. ( $\mathrm{N}=718)$, las cuales también presentan coloración oscura, esto llevó a confusión en un primer momento e hizo que fueran consideradas en los análisis. En este caso ninguna de las semillas correspondía a ejemplares carbonizados (de manera que fueron retiradas del análisis).

Dentro de los restos recuperados de maíz tenemos por un lado los granos, y por otro las estructuras que los contienen (marlo/cúpula). En esta última categoría debemos aclarar que consideramos: marlo cuando al resto se le pueden contabilizar las hileras de cúpulas, y cúpula cuando solo se conservó dicha estructura.

Todos los restos de semillas, endocarpos y partes de fruto de Prosopis sp. L. identificados en este trabajo se corresponden a los denominados "algarrobos blancos" o "algarrobos negros" en las etnotaxonomías contemporáneas del NOA y NEA (Arenas, 2003; Capparelli, 2007, 2008). A nivel taxonómico los mismos abarcan a Prosopis chilensis (Molina) Stuntz emend. Burkart y $P$. alba Griseb. (algarrobos blancos) y P. flexuosa D.C. y P. nigra (Griseb.) Hieron. (algarrobos negros) (Burkart, 1940, 1952; Boelcke, 1946; Cabrera, 1983; IBODA, 2016). Dado que no hay un nivel de agregación taxonómica que agrupe estas etnocategorías, dejamos asentado que a lo largo de este trabajo, con la anotación Prosopis spp. nos referimos a las cuatro especies antes mencionadas y no a otros miembros del género, motivo por el cual ocasionalmente nos referiremos también a estos restos como "algarrobos". En algunos casos se han podido distinguir los restos correspondientes a algarrobos blancos de los de algarrobos negros, en el primer caso los mismos se consignan como Prosopis spp. aff. alba/chilensis y en el segundo como Prosopis spp. aff. flexuosa/nigra (ver Tabla 1).

\section{Grados de asociación}

En el sitio Soria 2 se identificaron solo dos especies domesticadas y, por lo tanto, cultivadas: el maíz (Zea mays L.) y la quínoa (Chenopodium quinoa Willd. var. quinoa). Asimismo, se identificaron dos taxa silvestres: Prosopis spp. aff. flexuosa/nigra/alba/chilensis y Geoffroea decorticans (Gillies ex Hook. \& Arn.) Burkart (chañar). Los mismos prosperan en el área de estudio y, si bien en el caso del algarrobo se ha mencionado la posibilidad de cultivo prehispánico del mismo (Mc Rostie, 2016), teniendo en cuenta el estado actual de las investigaciones para el área, consideraremos la presencia de carporrestos de ambos como producto de la recolección.

En cuanto a Chenopodium aff. carnosulum Moq., una hipótesis planteada al respecto del origen de la quínoa, es que durante su evolución participaron parientes silvestres diploides, realizando aportes significativos en su genoma, así, C. carnosulum le 
Bol. Soc. Argent. Bot. 54 (1) 2019

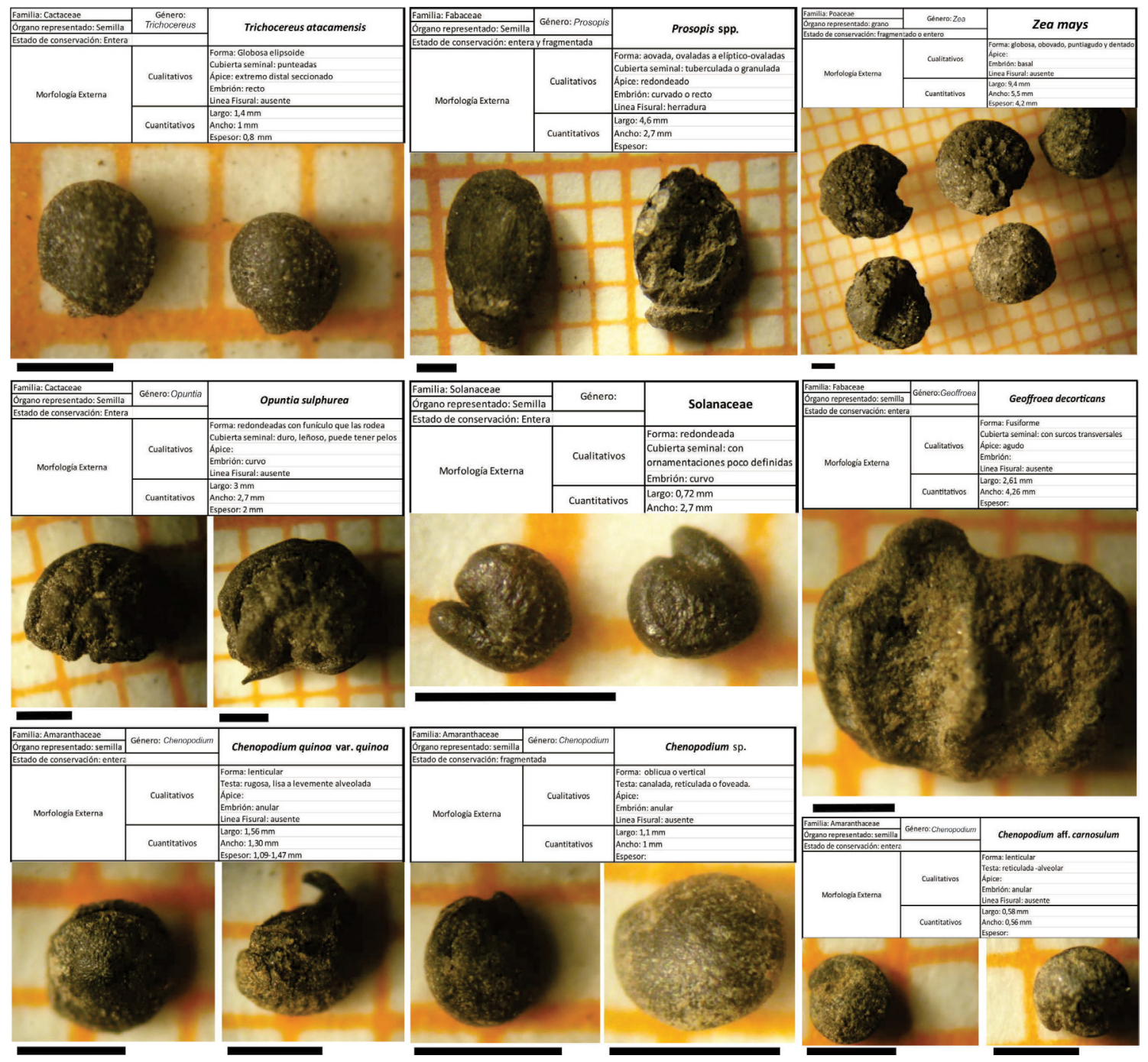

Fig. 3. Carporrestos recuperados por la técnica de flotación del sitio temprano Soria 2

otorgó a la quínoa domesticada gran tolerancia a la salinidad, $C$. petiolare Kunth resistencia a la sequía y $C$. pallidicaule Aellen resistencia al frío (Mujica \& Jacobsen, 2006). Si bien C. carnosulum prospera por fuera de los campos cultivados, también puede estar presente en los mismos y participar del flujo génico con otros miembros del género, por lo cual la consideramos como una maleza facultativa. Los restos determinados como Chenopodium sp. L. no se corresponden con la quínoa ni con $C$. carnosulum, por lo cual, si bien estamos en condiciones de afirmar que no se trata de restos de la forma domesticada, puede tratarse tanto de formas malezoides como silvestres y por lo tanto sujetas a prácticas de recolección, tolerancia, erradicación, fomento o cultivo (sensu stricto).

Las cactáceas fueron identificadas a nivel genérico. En el caso de Opuntia sp. Mill., la misma puede pertenecer-considerando las especies que prosperan en el área de estudio- a Opuntia anacanta Speg., O. ficus indica (L.) Mill., O. quimilo K. Schum., O. salmiana Parm., O. schickendantzii F.A.C. Weber y O. sulphurea Gillies ex Salm-Dyck (IBODA, 2016). En todos los casos se trata de especies silvestres y si bien podrían tener un comportamiento malezoide, no hemos hallado estudios que avalen esta propuesta, por lo cual será considerada como silvestre y asociada a prácticas de recolección. 


\section{N. Petrucci y R. Spano - Arqueobotánica del sitio temprano Soria 2}

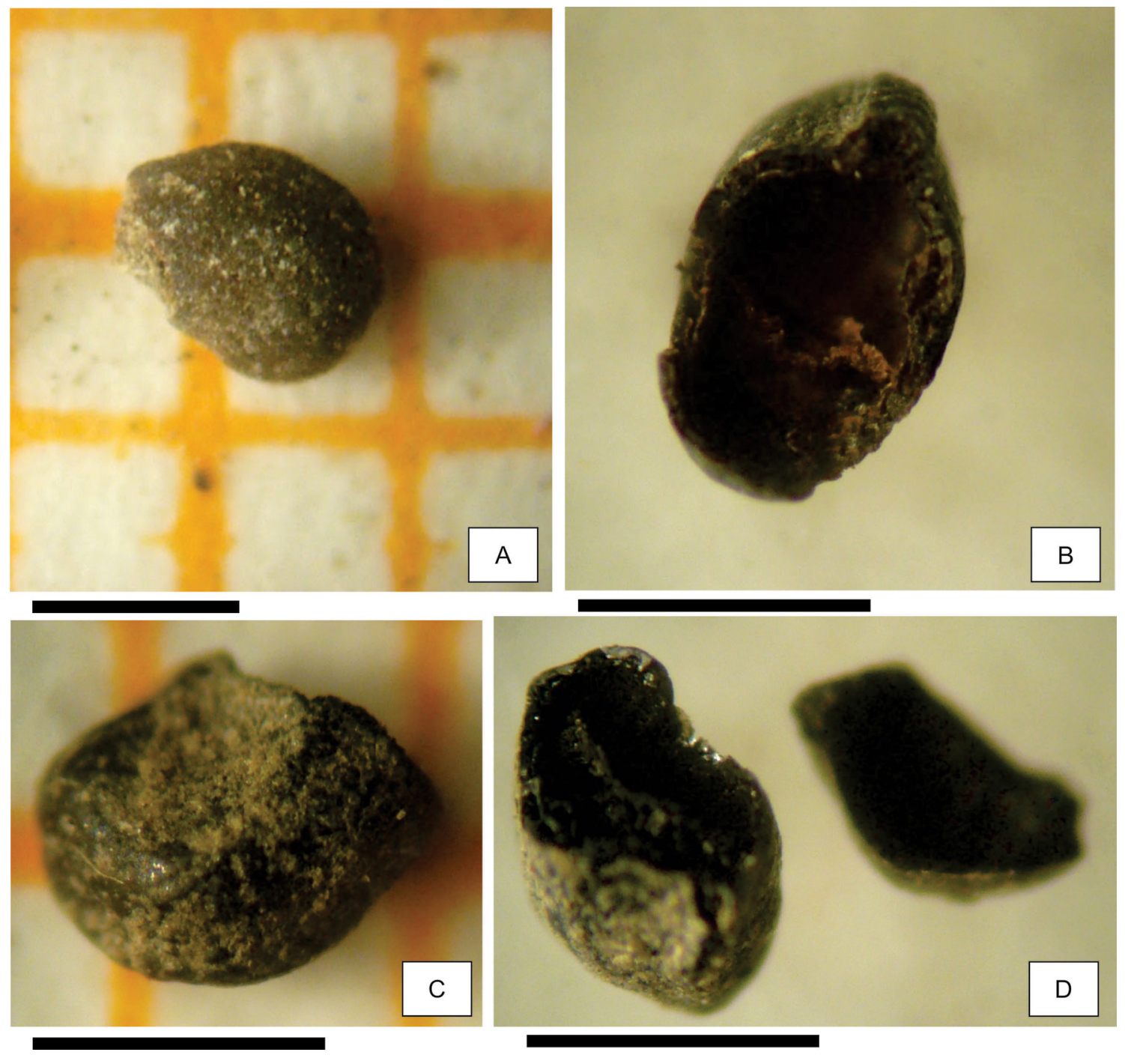

Fig. 4. A-B: semilla de Trichocereus sp. seca, recuperada del nivel 7, R2 del sitio Soria 2, C-D: semilla de Trichocereus sp. carbonizada recuperada del nivel 8, R1 del sitio Soria 2.

En el caso de los restos de semillas de Trichocereus sp., los mismos pueden corresponder a las especies T. andalgalensis (F.A.C. Weber) Hosseus, T. atacamensis (Phill.) Backeb., T. cabrerae R. Kiesling, T. huascha (F.A.C. Weber) Britton \& Rose, T. tarijensis (Vaupel) Werderm. y T. terscheckii (Parm. ex Pfeiff.) Britton \& Rose (IBODA 2016); asimismo, los herbarios de la zona indican que en la misma prospera $T$. atacamensis. Halloy (2008) ha planteado que los miembros del género podrían servir de indicadores de cambios climáticos pasados y uso de la tierra, a partir de su forma de crecimiento, longevidad y la tendencia a concentrarse en antiguas ruinas pre hispánicas. El trabajo realizado por Rodríguez-Arévalo y colaboradores (2006) sobre cactus columnares en México plantea que la mayor abundancia de individuos está asociada a sitios perturbados por el establecimiento de poblaciones humanas. En este sentido, y considerando el hábito de las malezas de prosperar en ambientes con disturbio antrópico, los restos de semillas de Trichocereus sp. podrían catalogarse como malezas facultativas no agrícolas y por lo tanto de tipo ruderal. 
Los dos restos de leguminosas que no pudieron identificarse con más precisión no se corresponden a restos de plantas domesticadas de la familia propias de la zona, ni corresponden a la sección Mimosoidea, ni a los taxa registrados en los herbarios elaborados para la zona. Existiendo tanto formas silvestres como malezas de la familia (Burkart, 1940, 1952; Rapoport et al., 2009) y que los restos pueden corresponderse por su morfología y anatomía tanto a unas como a otras, solo podemos afirmar que no se trata de especies domesticadas.

En lo que respecta a carporrestos de semillas de Solanaceae, los herbarios realizados para la zona mencionan a Lycium chilense Miers ex Bertero y Solanum sisymbriifolium Lam., esta última maleza del maíz. Las comparaciones con ambas especies no ha dado resultados definitorios, tampoco ha sido coincidente con otras Solanaceas registradas a nivel arqueobotánico como Solanum eleagnifolium Cav. (Capparelli, 2009; Lema, 2009, 2014) o Solanoides (género Solanum L. o Capsicum L.) (Calo, 2010). Habiendo descartado que las semillas identificadas en este trabajo correspondan a especies domesticadas de la familia, podemos considerar a las mismas como representativas de formas silvestres o malezoides.

\section{Distribución de los carporrestos}

Cuando analizamos el material recuperado en el sitio en su conjunto, sin diferenciar los restos recuperados en cada recinto ni los asociados a los niveles de ocupación, tenemos que del total de los carporrestos $(\mathrm{N}=251)$, se pudieron identificar taxonómicamente el $90,44 \%$, dentro de los cuales se encuentran los siguientes taxa y órganos: semillas de Trichocereus sp. (52,6\%), semillas de Geoffroea decorticans $(9,6 \%)$, granos de Chenopodium sp. (5,9\%), semillas de Opuntia sp. (1,6\%), semillas y endocarpos de Prosopis spp. (2,4\%), marlo/cúpula y granos de Zea mays $(4,8 \%)$ y semillas de Solanaceae (3,6\%). El taxón más abundante, de manera destacada, es Trichocereus sp., seguido del chañar, encontrándose los demás presentes en cantidades similares entre sí. A lo anterior se suma que Trichocereus sp. es el taxón más ubicuo, seguido por los ejemplares pertenecientes al género Chenopodium y a la especie Geoffroea decorticans (Fig. 5).

$\mathrm{Al}$ analizar lo que se sucede en los niveles asociados a la ocupación temprana de forma comparativa entre los recintos R1 y R2, observamos que Trichocereus sp. es el taxa con mayor densidad (Fig. 6), seguidos por los restos de chañar que son los más abundantes, sobre todo y de manera notable, en el patio.

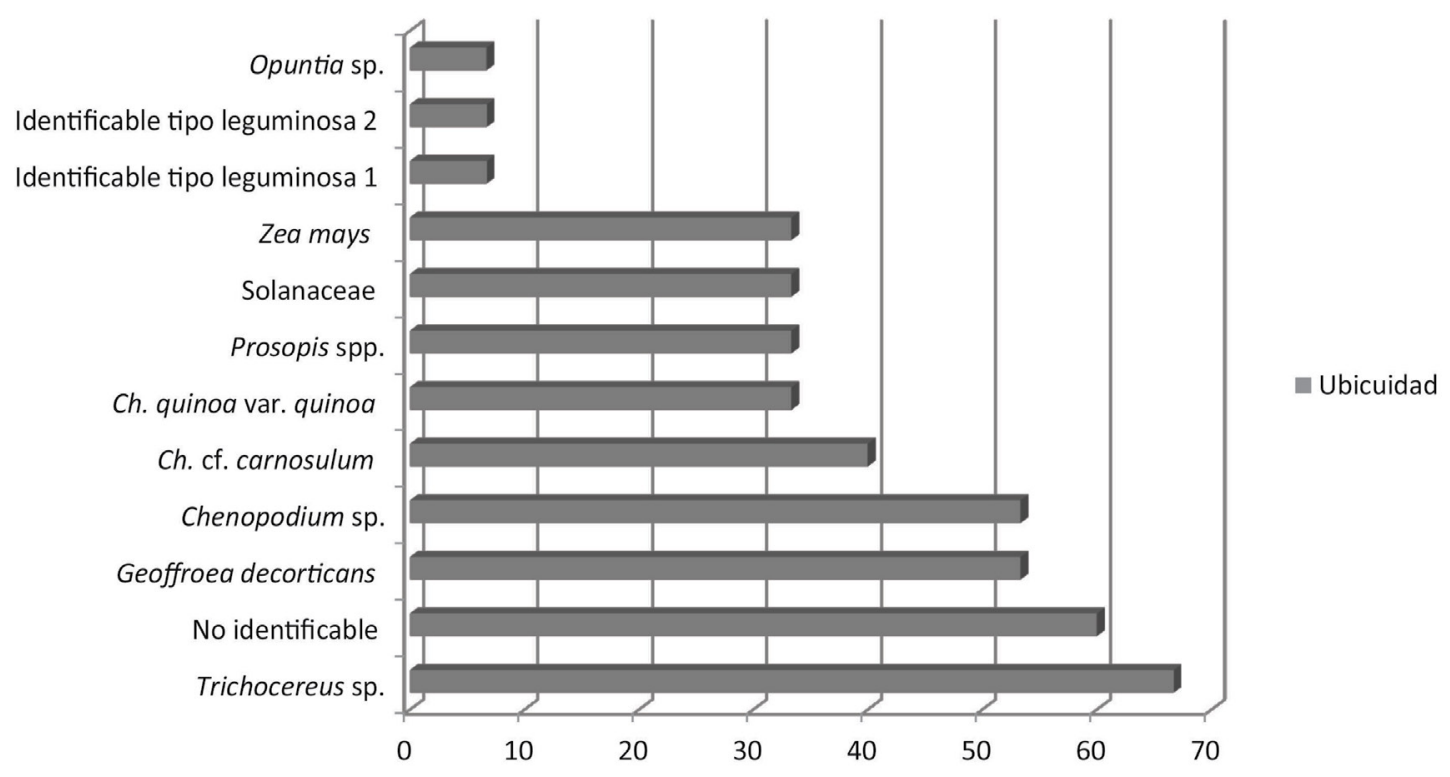

Fig. 5. Ubicuidad de taxa en el sitio Soria 2. 


\section{N. Petrucci y R. Spano - Arqueobotánica del sitio temprano Soria 2}

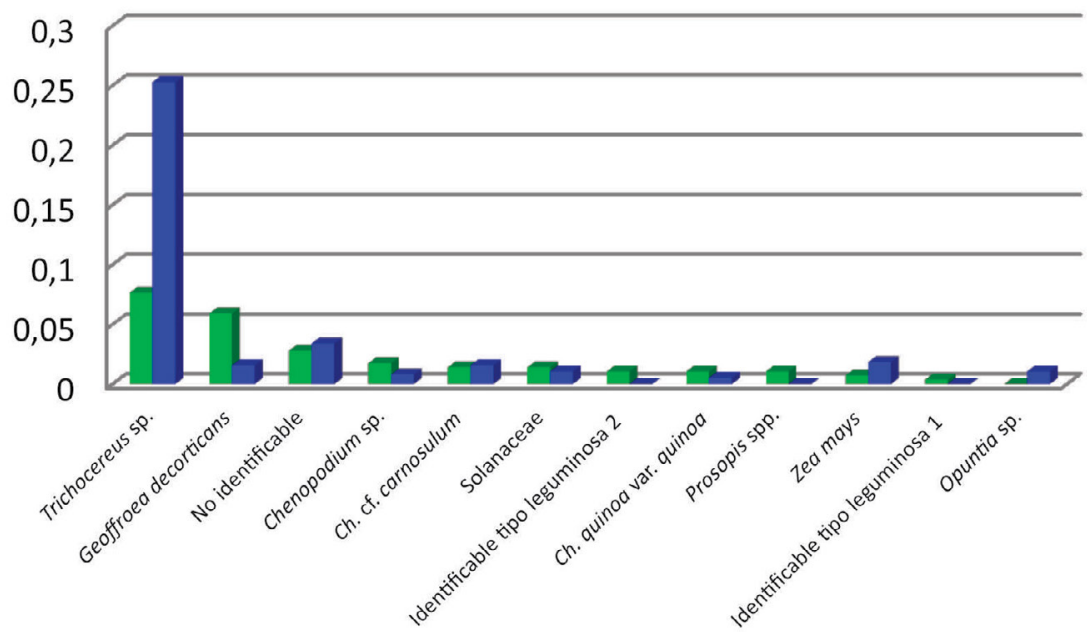

Densidad R1

Densidad R2

Fig. 6. Densidad de taxa de los recintos R1 y R2, asociada a los niveles de ocupación temprana del sitio Soria 2.

Al analizar la ubicuidad entre los recintos, observamos diferencias significativas (Fig. 7). El taxón con mayor presencia en los recintos R1 y R2 sigue siendo Trichocereus sp., seguido de ejemplares del género Chenopodium. Geoffroea decorticans y $C$. aff. carnosolum tienen mayor presencia en el patio, los restos de algarrobo y los ejemplares afines a leguminosas solo están presentes en dicho recinto. El maíz, restos de solanáceas y de quínoa son más abundantes en el R2, recinto donde están presentes las semillas de Opuntia sp. de manera exclusiva. Con respecto a los restos de maíz sólo se

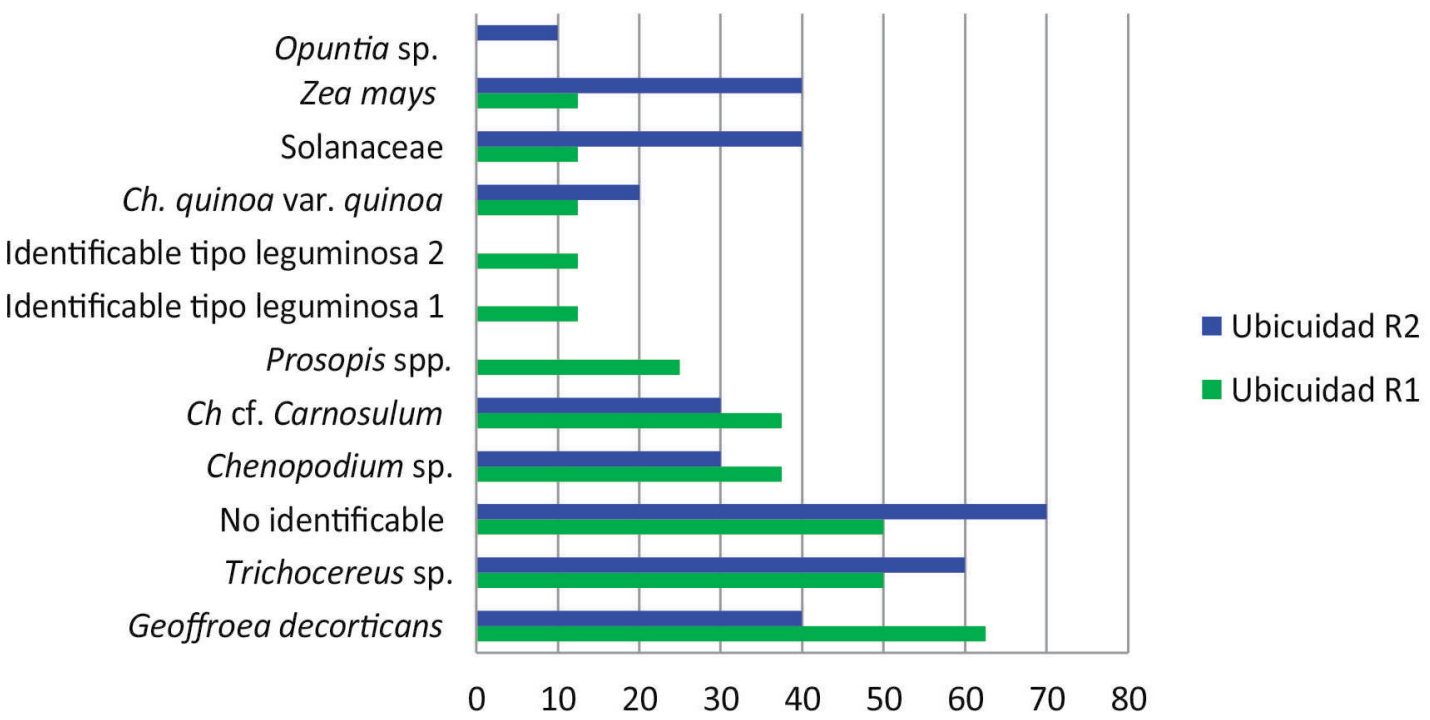

Fig. 7. Ubicuidad de taxa de los recintos $\mathrm{R} 1$ y $\mathrm{R} 2$ asociada a los niveles de ocupación temprana del sitio Soria 2. 
recuperaron marlos en $\mathrm{R} 1$, mientras que en $\mathrm{R} 2$ granos y marlos. Estas diferencias de presencia /ausencia de taxa y de proporciones entre los mismos, podrían sugerir prácticas diferenciales entre los espacios (recintos) que componían esta unidad domestica temprana. Las diferencias de presencia/ausencia antes mencionadas entre algarrobo y Opuntia sp. entre R1 y R2 no se reflejan en densidades disímiles. El análisis de densidad nos arroja una imagen diferente respecto al de ubiquidad en el caso de $C$. aff. carnosolum el cual posee una frecuencia de aparición (ubicuidad) mayor en el patio, pero es más abundante en el R2; la misma situación ocurre con los ejemplares de Solanaceae que eran más ubicuos en el R2, pero son más densos en R1.

Finalmente, si combinamos ubicuidad (en tanto presencia/ausencia) y densidad en R1 y R2 (tabla
2) vemos que el patio tiene más densidad de restos y mayor riqueza taxonómica por lo cual puede considerarse que en el mismo se llevaron a cabo de manera más intensa prácticas vinculadas a las plantas y/o una limpieza menos intensa.

$\mathrm{Al}$ agrupar los taxa recuperados en los niveles de ocupación, según su grado de asociación vemos que las malezas ruderales son las que mayores densidades presentaron, seguidas por las silvestres (Fig. 8), en tanto que el resto presentó porcentajes de densidad similares. El conjunto carpológico del sitio nos sugiere la presencia y el aprovechamiento de ambientes disturbados y no disturbados junto a espacios de cultivo indicados por plantas domesticadas y malezas agrícolas para momentos tempranos.

Tabla 2. Ubicuidad y densidad de taxa en los recintos 1 y 2 del sitio Soria 2 . X: presencia/ausencia (ubicuidad); + y -: mayor y menor densidad respectivamente.

\begin{tabular}{|lcc|}
\hline \multicolumn{1}{|c}{ Taxa } & R1 (patio) & R2 (unidad habitacional) \\
\hline Trichocereus sp. & $\mathrm{X}(-)$ & $\mathrm{X}(+)$ \\
Zea mays & $\mathrm{X}(-)$ & $\mathrm{X}(+)$ \\
Chenopodium aff. carnosulum & $\mathrm{X}(-)$ & $\mathrm{X}(+)$ \\
Geophroea decorticans & $\mathrm{X}(+)$ & $\mathrm{X}(-)$ \\
Chenopodium quinoa var. quinoa & $\mathrm{X}(+)$ & $\mathrm{X}(-)$ \\
Chenopodium sp. & $\mathrm{X}(+)$ & $\mathrm{X}(-)$ \\
Solanaceae & $\mathrm{X}(+)$ & \\
Identificable tipo leguminosa 1 & $\mathrm{X}$ & \\
Identificable tipo leguminosa 2 & $\mathrm{X}$ & $\mathrm{X}$ \\
Prosopis spp. cf. flexuosalnigra/alba/chilensis & $\mathrm{X}$ & \\
Opuntia sp. & & \\
\hline
\end{tabular}

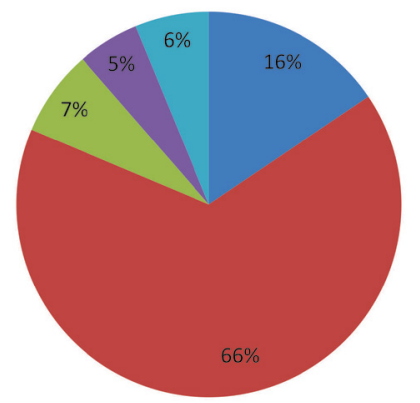

Fig. 8. Taxa identificados en los niveles ocupacionales de Soria 2 agrupados de acuerdo a su tipo de asociación con poblaciones humanas (porcentajes calculados a partir de valores de densidad).
- Silvestre

- Maleza ruderal

Domesticado

- Maleza agric.

no dom.

\section{Discusión}




\section{N. Petrucci y R. Spano - Arqueobotánica del sitio temprano Soria 2}

mismos pueden estar termo-alterados ya que se empleaban como combustible de fogones (como los marlos de maíz), porque forman partes de las heces de los animales utilizadas como combustible (Pearsall, 1989), o bien por limpieza de los recintos, sobre todo en casos donde el procesamiento de los alimentos no implicaba contacto con el fuego, como en el caso de los frutos de algarrobo (Capparelli, 2008, 2011), a los cuales podemos sumar los restos de semillas de frutos de cactáceas como los de los géneros Trichocereus y Opuntia recuperados, al igual que restos de potenciales malezas agrícolas que ingresan a los recintos con las cosechas (Pearsall, 1989). También debe considerarse para el caso de granos de maíz y quinoa, que las partes utilizables pudieron entrar en contacto con el fuego constituyendo desechos de comida, caídas accidentalmente durante la cocción, o ejemplares descartados por daño (Munson et al., 1971), aunque para evaluar estas posibilidades son necesarios estudios de procesamiento.

Las modificaciones ocasionadas en los ejemplares por la carbonización $-\mathrm{y}$ posiblemente por el procesamiento- generaron en algunos casos distorsiones de los caracteres morfológicos cualitativos y cuantitativos dificultando su identificación. Análisis histológicos, así como ensayos experimentales de carbonización de distintas partes de plantas, son herramientas que probablemente permitirán en el futuro la posibilidad de identificar estos restos afectados por la combustión. En otros casos los efectos de estos procesos redujeron la posibilidad de identificaciones a nivel genérico o específico, por ejemplo, con los ejemplares de la familia Solanaceae, y del género Chenopodium, limitando también nuestras capacidades de proyección interpretativa sobre los mismos.

Uno de los objetivos de este trabajo fue procurar identificaciones taxonómicas lo más precisas posible. Como señalamos anteriormente, además de aspectos taxonómicos y de la combustión misma, el procesamiento atenta contra la conservación de rasgos diagnósticos para identificaciones taxonómicas de distinto orden. Esto llevó, en nuestro caso de estudio, a que varios restos no pudieran ser identificados con mayor precisión o bien a que directamente no pudieran ser identificados. En relación a este último aspecto propusimos una categoría para los ejemplares que por su estado de conservación no permitía apreciar caracteres básicos de clasificación taxonómica, pero que correspondían a restos vegetales, denominados "no identificables". En muchos casos, se realizaron aproximaciones taxonómicas que nos sirvieron para poder diferenciar entre distintas formas de los miembros de determinada categoría. Un ejemplo de esto son los ejemplares no identificados que llamamos "Identificable tipo Leguminosa 1" e "Identificable tipo Leguminosa 2", que por sus caracteres pudimos estimar que no se trataba de ninguna forma domesticada de la familia Fabaceae, ni pertenecientes a la Subfamilia Mimosoideae y que no comprendía a formas domesticadas de dicha familia. Los restos clasificados como identificables son aquellos que sí poseen rasgos característicos bien conservados pero que, sin embargo, no pudieron determinarse hasta el momento. Otra identificación a nivel de familia fueron las Solanaceae, sobre las cuales no se pudo ofrecer más precisión ya que no se contaba con las claves de identificación, o bien las mismas se basaban en caracteres que se ven afectados por la carbonización (como la presencia de pelos); tampoco contábamos con semillas de todos los ejemplares actuales más allá de los herbarios de referencia del área. En este sentido remarcamos la importancia de las colecciones de referencia para el estudio de restos arqueobotánicos, ya que permiten la identificación taxonómica y procesos particulares de combustión (Capparelli et al., 2015). Solanaceae es una familia muy vasta, con miembros de muy diverso uso y grados de asociación con las poblaciones humanas, además de ser recurrente en los sitios arqueológicos del NOA. Contar a futuro con mayores posibilidades de reconocimiento de las mismas servirá para enriquecer la comprensión de prácticas pasadas. Tómese como ejemplo nuevamente el caso de la familia de las leguminosas ${ }^{1}$, la cual posee representantes desde silvestres a domesticados, con porte variado yendo desde hierbas hasta árboles de usos diversos (alimenticio, medicinal, psicoactivo, entre otros). Procurar ir más allá de una identificación general que englobe a todas las

\footnotetext{
El análisis químico del contenido de una de las pipas recuperadas en este sitio permitió identificar la presencia de alcaloides producidos por Anadenanthera colunbrina var. cebil, especie psicoactiva ampliamente utilizada en el Noroeste Argentino prehispánico (Rosso \& Spano, 2005-2006).
} 
leguminosas (ver por ejemplo D'Altroy et al., 2000) y precisar los taxa presentes, particularmente en el caso del género Prosopis y sus especies de vainas comestibles como alba, nigra, chilensis y flexuosa (Capparelli, 1997; Oliszewski, 1999, 2004) al igual que avanzar en la interpretación de sus modalidades de consumo y procesamiento (Capparelli, 2007, 2008, 2011), ejemplifica la importancia de precisar los estudios de identificación.

En los sitios donde, por condiciones climáticas, no se conservan los restos en estado seco, considerándose los restos que se encuentran en estado carbonizado como pertenecientes a la ocupación, como en el sitio bajo estudio, existe la posibilidad de confusión con las semillas de color negro, ya que la combustión produce, entre otras consecuencias, una alteración en el color de los tejidos tornándolos a una coloración negra. En el sitio Soria 2, dos carporrestos que se recuperaron en gran cantidad, Trichocereus sp. $(\mathrm{N}=988)$ y Portulaca sp. $(\mathrm{N}=718)$, poseen semillas de color negro, lo cual en un primer momento generó confusión e hizo que fueran consideradas en los análisis. Para corroborar que las mismas se encontraban carbonizadas, y que su color no se debía a su tono natural, se optó por realizar cortes transversales de cada una de las semillas para la observación de los tejidos internos. Con respecto a estos dos taxa, los mismos fueron encontrados en otros sitios: Trichocereus sp. en El Shincal no fue computado ya que los restos fueron considerados como secos (Capparelli, 2016 com. pers.), y en El Pichao, donde se recuperaron carporrestos de Trichocereus sp. y Portulaca sp. (Cano, 2011). En este último sitio, el autor no especifica si realizó alguna prueba para corroborar que se trataban de ejemplares carbonizados. Distinto es el caso cuando se consideran ejemplares secos procedentes de sitios de buena preservación como son las cuevas, por ejemplo, la identificación de presencia de Trichocereus aff. pasacana en la capa E1 de la cueva III de Huachichocana en Jujuy (Fernández Distel, 1974).

\section{Interpretación del sitio a partir de la integración de estudios previos y los restos arqueobotánicos}

En el sitio Soria 2, las diferencias de presencia/ ausencia de taxa y de proporciones entre los R1 y R2, podrían indicar actividades diferenciales efectuadas en el pasado entre ambos, sugiriendo prácticas con anclaje espacial dentro de la unidad doméstica. Vemos por ejemplo que el patio tiene más densidad de restos y mayor riqueza taxonómica, por lo cual puede considerarse que en el mismo se llevaron a cabo de manera más intensa prácticas vinculadas a las plantas y/o una limpieza menos cuidada.

El análisis de cactáceas abre una puerta de indagación interesante que no ha sido ampliamente estudiada en otros sitios de la región. En primer lugar, y como ya mencionamos, los restos de Trichocereus sp. nos indican el aprovechamiento de especies con tendencia malezoide de tipo ruderal de forma muy notable en este sitio, lo cual podría llegar a estar sugiriendo una configuración del paisaje donde los cardonales fueron quizá tolerados en estos asentamientos que se encontraban dispersos en los campos de cultivo. Estas malezas (no agrícolas) recuperadas en el sitio nos indican la presencia de espacios disturbados y el aprovechamiento de los frutos de cardones (Trichocereus sp.).

Cuando comparamos los recintos, observamos que por ejemplo en el recinto definido como patio se encontraron cúpulas/marlos de maíz, pero no granos, y en el recinto R2 se encontraron ambos tipos de restos, teniendo mayor presencia los granos. En un análisis previo se pudo identificar que los mismos eran de tipo redondo, de endosperma vítreo, sin pericarpio y presentaban evidencias de cocción incompleta (Petrucci \& Lema, 2016). La ausencia de pericarpio nos alerta acerca de la posibilidad de que los granos hayan sido hervidos con cenizas para su pelado; la cocción incompleta nos sugiere que el hervido tuvo que ver más con un pre-tratamiento del grano para quitar el pericarpio que con su cocción completa para consumo. El hallazgo de este tipo de restos en el R2 nos podría hablar de granos de maíz pre-tratados y almacenados para su posterior consumo. En Andreoni et al. (2012) se comunicó la identificación de microrrestos de granos de almidón de maíz (Zea mays) -entre otros elementos- remanentes en el contenido carbonizado de un hornillo de pipa cerámica hallada en R1. Esta presencia fue interpretada por los autores como producto de la utilización y/o el descarte del artefacto en un contexto doméstico en el cual se estuvo procesando maíz. Tomando en consideración la volatilización del maíz molido y su eventual dispersión más allá del espacio de actividad, los granos de almidón pudieron haber quedado atrapados en el contenido 


\section{N. Petrucci y R. Spano - Arqueobotánica del sitio temprano Soria 2}

de la pipa. Esta identificación ofrece evidencia para bosquejar las prácticas acaecidas en este espacio doméstico, sugiriendo la "coexistencia" de las actividades de moler y fumar (Andreoni et al., 2012). Se ha propuesto una situación semejante de coexistencia de actividades en el sitio temprano Cardonal situado en el vecino valle del Cajón (Bugliani et al., 2010).

Lo mismo planteamos para los restos de quinoa y los ejemplares del género Chenopodium que no pudieron determinarse con más precisión, que presentaron mayores densidades en el recinto R2, mientras que se encontraron en menores densidades junto con la maleza en el patio. Esta diferencia en la distribución permitiría realizar algunas inferencias, pero en este caso también creemos que el análisis de procesamiento posibilitaría una aproximación más ajustada en esta diferenciación de los espacios marcada por los restos. Granos de Chenopodium sp., recuperados en el referido sitio Cardonal estaban representados únicamente en la estructura definida como patio; los mismos presentaron evidencias de hervido y posterior carbonización (Calo, 2010). En dicho sitio también se identificaron restos escasos de algarroba afines a la etnovariedad blanco (Calo, 2010). En Soria 2 se presentaron restos de este tipo y también de algarroba negra en el patio, donde asimismo se hallaron semillas de chañar y artefactos de molienda individuales móviles. Esto sugiere que en el patio pudieron molerse frutos de algarrobos, chañares y posiblemente maíz-ya que dicha práctica desintegra el grano-.

Como mencionamos, $C$. aff. carnosulum fue recuperada junto a la especie domesticada $C$. quinoa var. quinoa. Esta asociación nos sugiere no solo que haya sido posiblemente maleza obligada de la quinoa, sino también que las mismas pudieron ser toleradas (o incluso fomentadas, cultivadas sensu lato) y de esta manera ingresar a los recintos junto con la forma domesticada cultivada. Podemos pensar en un ingreso accidental junto a la cosecha, o bien en uno intencional con el fin de consumir sus hojas como verdura o sus granos en alguna preparación. Descartamos la erradicación, ya que si se hubiese llevado a cabo dicha práctica de forma intensiva y sostenida, no existiría posibilidad de ingreso de estas malezas a los recintos, - el desmalezado se habría realizado en el propio campo de cultivo y quizás haya sido descartado en las inmediaciones-. Vimos también que otras formas silvestres o malezoides de Chenopodium sp. se hacen presentes, reforzando la idea de complejos silvestre-maleza-domesticado en momentos tempranos (Lema, 2014; Korstanje et al., 2015; Martínez et al., 2015).

Finalmente, el conjunto carpológico del sitio nos sugiere la presencia y el aprovechamiento de ambientes disturbados y no disturbados junto a espacios de cultivo indicados por plantas domesticadas y malezas agrícolas. En este sentido es sugerente pensar que la división patio/habitación dentro de la unidad doméstica podría no solo marcar distintas actividades, sino también la alusión semántica a paisajes extra vivienda: algarrobales, chañarales y cardonales en el patio, y campos de cultivo sembrados con granos en la habitación. Más allá del sitio, un mundo por recuperar en la fracción fina y la pesada.

\section{Contribución DE los AUtORES}

RS dirigió las excavaciones en el sitio Soria 2. RS y NP realizaron la flotación de los sedimentos. La identificación y análisis de los restos arqueobotánicos estuvo a cargo de NP. Interpretación e integración con todos los hallazgos NP y RS. Todos los autores participaron en la redacción del manuscrito.

\section{Agradecimientos}

A la Dra. Verónica Lema y la Dra. María Lelia Pochettino quienes ayudaron en todo el proceso de identificación y análisis de las muestras. A la Dra. Myriam Tarragó, quien como directora del Proyecto Arqueológico Yocavil, alienta y refuerza nuestra pasión por esta carrera. A las Dras. Aylen Capparelli y María Laura López, que colaboraron en el análisis de los restos botánicos. A la Dra. Valeria Palamarczuk, impulsora del "regreso" de la flotación.

\section{Bibliografía}

ÁLVAREZ LARRAIN, A. 2009. Teledetección y análisis del uso del espacio en el sudeste del Valle de Santa María (depto. de Santa María, prov. de Catamarca). Tesis de Licenciatura en Cs. Antropológicas (orientación Arqueología). F.F.y L., UBA. Ms. 
ÁLVAREZ LARRAIN, A. 2014. Habitar una región. Espacialidad arquitectónica y construcción de paisajes en Andalhuala, valle de Yocavil (Catamarca, Argentina). Tesis de Doctorado en Arqueología. FFyL, UBA. Ms.

ANDREONI, D., R. C. SPANO \& V. LEMA. 2012. Nota sobre evidencias de uso de plantas en el sitio Soria 2 a partir del análisis microscópico del contenido de pipas. Arqueología 18: 235-243.

ARENAS, P. 2003. Etnografia y alimentación entre los Toba-Nachilamoleek y Wichi-Lhuku'tas del Chaco Central (Argentina), Edición del autor.

BELOTTI LÓPEZ MEDINA, C. 2011. Zooarqueología del sitio formativo Soria 2, valle de Santa María (Catamarca), siglo I d.C. Revista del Museo de Antropología 4: 3-16.

BOELCKE, O. 1946. Estudio morfológico de las semillas de leguminosas Mimosoideas y Cesalpinioideas de interés agronómico en Argentina. Darwiniana 7: 240-321.

BUGLIANI, M. F., M. CALO \& M. C. SCATTOLIN. 2010. ¿Fumando en la cocina? Determinación de contenidos por técnicas fisicoquímicas en dos pipas cerámicas del sitio Cardonal. En BERTOLINO, S., R. CATTÁNEO \& IZETA, A. (eds.), La arqueometría en Argentina y Latinoamérica, pp. 231-236. Córdoba.

BURKART, A. 1940. Materiales para una monografía del género Prosopis (Leguminosae). Darwiniana 4: 57-128.

BURKART, A. 1952. Las Leguminosas argentinas silvestres y cultivadas, 2da. ed. Buenos Aires: Acme.

BUXÓ, R. 1997. Arqueología de las plantas. La explotación económica de las semillas y los frutos en el marco mediterráneo de la Península Ibérica. Crítica, Barcelona.

CABRERA, A. L. 1971. Fitogeografía de la República Argentina. Bol. Soc. Argent. Bot. 14 (1-2).

CABRERA, A. L. 1976. Regiones fitogeográficas argentinas. Enciclopedia Argentina de Agricultura y Jardinería, T. 2(1). ACME, Buenos Aires.

CABRERA, A. L. 1983, Flora de Jujuy. INTA, Jujuy.

CALO, M. 2010. Plantas útiles y prácticas cotidianas entre los aldeanos al sur de los valles Calchaquíes (600 a.C.900 a.C.). Tesis de doctorado. FCNyM, UNLP.

CANO, S. 2011. Utilización de Recursos Vegetales y Subsistencia en el Valle de Santa María durante el Periodo de Desarrollos Regionales: Un Caso de Estudio en el Sitio El Pichao (S Tuc Tav 5). Tesis de grado. F.C.N. e I.M.L. U.N.T.

CAPPARELLI, A. 1997. Reconstrucción ambiental de la instalación arqueológica Inka El Shincal. Tesis de doctorado. FCNyM, UNLP.

CAPPARELLI, A. 2007. Los productos alimenticios derivados de Prosopis chilensis (Mol.) Stuntz y $P$. flexuosa DC., Fabaceae, en la vida cotidiana de los habitantes del NOA y su paralelismo con el algarrobo europeo. Kurtziana 3: 1-19.
CAPPARELLI, A. 2008. Caracterización cuantitativa de productos intermedios y residuos derivados de alimentos del algarrobo (Prosopis flexuosa DC y $P$. chilensis (Mol.) Stuntz, Fabaceae): aproximación experimental aplicada a restos arqueobotánicos desecados. Darwiniana 46 (2): 175-201.

CAPPARELLI, A. 2009. Intra-site comparison of the archaeoethnobotanical evidence of El Shincal: implicances to the Inka economy. Treballs d'Etnoarqueologia 7: 113-144.

CAPPARELLI, A. 2011. Elucidating post-harvest practices involved in the processing of algarrobo (Prosopis spp.) for food at El Shincal Inka site (Northwest Argentina): an experimental approach based on charred remains. Archaeol Anthropol Sci 3: 93-112. https://doi.org/10.1007/s12520-011-0061-4

CAPPARELLI, A, M. L. POCHETTINO, V. LEMA, M. L. LÓPEZ, D. ANDREONI, M. L. CIAMPAGNA \& C. LLANO. 2015. The contribution of ethnobotany and experimental archaeology to interpretation of ancient food processing: methodological proposals based on the discussion of several case studies on Prosopis spp., Chenopodium spp. and Cucurbita spp. from Argentina. Veg Hist Archaeobot 24:151163. https://doi.org/10.1007/s00334-014-0497-4

CARBONELLI, J. 2009. Interacciones cotidianas entre materias primas y sujetos sociales en el Valle de Yocavil. El caso del sitio Soria 2 (Andalhuala, Pcia. de Catamarca). Tesis de licenciatura en Cs. Antropológicas (orientación en Arqueología) F.F. y L., UBA.

CARBONELLI, J. 2011. Motivos porque y para en la tecnología lítica de un sitio formativo en el Valle de Santa María, provincia de Catamarca. Intersecciones en Antropología 12: 31-45.

CASAS, A. 2001. Silvicultura y domesticación de plantas en Mesoamérica. En AGUILAR, B.; S., DOMÍNGUEZ; J. CABALLERO NIETO y MARTÍNEZ ALFARO (eds.), Plantas, cultura $y$ sociedad. Estudio sobre la relación entre seres humanos y plantas en los albores del siglo XXI. M. UAM-S.M.A.R.N. y P. México.

DE WET, J. M. \& J. R. HARLAN. 1975. Weeds and Domesticates: evolution in the man-made hábitat. Econ.Bot. 29: 99-107. https://doi.org/10.1007/BF02863309

D'ALTROY, T., A. LORANDI, V. WILLIAMS, M. CALDEGARI, C. HASTORF, E. DEMARRAIS \& M. HAGSTRUM. 2000. Inka Rule in the Northern Calchaquí valley, Argentina. J. Field Archaeol. 27: $1-26$.

FERNÁNDEZ DISTEL, A. 1974. Excavaciones arqueológicas en las cuevas de Huachichocana, Dep. de Tumbaya, Prov. de Jujuy, Argentina. Rel. Soc. Argent. Antropol. 8: 101-127. 


\section{N. Petrucci y R. Spano - Arqueobotánica del sitio temprano Soria 2}

FORD, R. 1979. Paleoethnobotany in American Archaeology. In M. B. SCHIFFER (ed.), Advances in archaeological method and theory. Vol 2, pp. 285-336. Academic Press. New York.

HALLOY, S. 2008. Crecimiento exponencial y supervivencia del cardón (Echinopsis atacamensis subsp. pasacana) en su límite altitudinal (Tucumán, Argentina). Ecol. Boliv. 43(1): 6-15.

HARLAN, J. 1992. Crops and man. Nueva York, American Society of Agronomy.

HARRIS, E. C. 1991. Principios de Estratigrafía Arqueológica. Crítica. Barcelona.

HARTMANN-SHENKMAN A, M. KISLEV, E. GALILI, Y. MELAMED \& E. WEISS. 2015. Invading a new niche: obligatory weeds at Neolitic Atlit-Yam, Israel. Veg Hist Archaeobot 24: 9-18. https://doi.org/10.1007/s00334-014-0498-3

HERBARIO MCNS. 2011. Flora del valle de Lerma. [Disponible en]: http://natura.unsa.edu.ar/web/index. $\mathrm{php} /$ herbario-mens/herbario/aportes-botanicossalta/flora-valle-de-lerma/detail. [Último acceso]: 24/10/2016.

IBODA. 2016. Flora del Conosur. Catálogo de Plantas Vasculares. [Disponible en]: http://www2.darwin. edu.ar/Proyectos/FloraArgentina. [Último acceso]: 24/10/16.

KORSTANJE A., M. QUESADA, V. FRANCO SALVI, V. LEMA V. \& M. MALOVERTI. 2015. Gente, tierra, agua y cultivos: los primeros paisajes agrarios del hoy noroeste argentino. En KORSTANJE A., LAZZARI M., BASILE M., BUGLIANI F., LEMAV., PEREYRA DOMINGORENA L. \& QUESADA M. (eds.), Crónicas materiales precolombinas. Arqueología de los primeros poblados del Noroeste Argentino, pp. 721-749. Sociedad Argentina de Antropología.

LEMA, V. 2009. Domesticación Vegetal y Grados de Dependencia Ser Humano-Planta en el Desarrollo Cultural Prehispánico del Noroeste Argentino. Tesis de doctorado. F.C.N.yM., UNLP.

LEMA, V. 2014. Boceto para un esquema: domesticación y agricultura temprana en el Noroeste argentino. Rev. Rsp. Antropol. Am. 44: 465-494.

MARTÍNEZ A., S. PÉREZ, V. LEMA \& F. LÓPEZ ANIDO. 2015. Modificación de caracteres ligados a la domesticación en Cucurbita maxima. Utilización de la morfometría como herramienta para su identificación. Acta Bot. Malac. 40: 95-106.

MCROSTIE, V. 2016. Algarrobales de Atacama. Nativos o exóticos? silvestres o domésticos? En Actas del XIX Congreso Nacional de Arqueología Argentina: 1539-1544.

MILLER, N. F. 1988. Ratios in Paleoethnobotanical Analysis. In C. HASTORF \& V. POPPER (eds.), Current Paleoetnobotany. Analytical Methods and Cultural Interpretations of Archaeological Plant Remains, pp. 72-85. University of Chicago, Chicago.
MORLANS, M. C. 1995. Regiones naturales de Catamarca. Provincias Geológicas y Provincias Fitogeográficas. Revista Ciencia y Técnica 2: 1-42.

MUJICA, A. \& S.E. JACOBSEN . 2006. La quinua (Chenopodium quinoa Willd.) y sus parientes silvestres. En M. MORAES R., B. OLLGAARD, L. P. KVIST, F. BORCHSENIUS y H. BALSLEV (eds.), Botánica Económica de los Andes Centrales, pp. 449457. Universidad Mayor de San Andrés, La Paz.

MUNSON, P. J., P. W. PARMALEE \& R. A. YARNELL. 1971. Subsistence ecology of Scovill, a terminal Middle Woodland village. Am. Antiq. 36: 410-431. https://doi.org/10.2307/278461

OLISZEWSKI, N. 1999. La importancia del algarrobo en el Campo del Pucará, Andalgalá, Catamarca) durante el período Formativo, En ASCHERO, C.; A. KORSTANJEY \& P. VUOTO (Eds.). Los tres reinos: prácticas de recolección en el cono sur de América, pp. 171-178. UNT, Tucumán, Argentina.

OLISZEWSKI, N. 2004. Utilización de recursos vegetales en Campo del Pucará (Andalgalá, Catamarca) durante el periodo formativo (200-500 DC). Análisis de macrorrestos. Tesis de doctorado. F.C.N. e I.M.L. U.N.T.

PALAMARCZUK, V., R. SPANO, F. WEBER, D. MAGNIFICO, S. LÓPEZ \& M. MANASIEWICZ. 2007. Soria 2. Apuntes sobre un Sitio Formativo en el Valle de Santa María (Catamarca, Argentina). Intersecciones en Antropol. 8: 121-134.

PEARSALL, D. 1989. Paleoethnobotany. A Handbook of Procedures. Academic Press. San Diego.

PETRUCCI, N. \& V. LEMA. 2016. Caracterización de procesamiento y carbonización de productos derivados de Zea mays L.: aproximación experimental aplicada a restos arqueobotánicos carbonizados. Intersecciones Antropol. 17:291-302.

POPPER, V. S. 1988. Selecting Quantitative Measurements in Paleoetnobotany. In C. HASTORF \& V. POPPER (eds.), Current Paleoetnobotany. Analytical Methods and Cultural Interpretations of Archaeological Plant Remains, pp. 53-71. The University of Chicago Press, Chicago.

RAPOPORT, E., A. MARZOCCA \& B. DRAUSAL. 2009. Malezas comestibles del cono sur y otras partes del planeta. Ed. Instituto Nacional de Tecnología Agropecuaria, Buenos Aires.

RODRÍGUEZ-ARÉVALO, I., A. CASAS, R. LIRA \& J. CAMPOS. 2006. Uso, manejo y procesos de domesticación de Pachycereus hollianus (F.A.C. Weber) Buxb. (Cactaceae), en el valle de TehuacánCuicatlán, México. Revista Interciencia 31 (9): $677-$ 685.

ROSSO, C. \& R. SPANO. 2005-2006. Evidencias del uso de alucinógenos en pipas halladas en dos sitios tempranos de los valles Cachaquíes. Arqueología 13: 79-98. 


\section{Bol. Soc. Argent. Bot. 54 (1) 2019}

SPANO, R. 2008. Indagaciones sobre las sociedades aldeanas del valle de Santa María; análisis de la alfarería fina del sitio Soria 2 (Andalhuala, Pcia. de Catamarca). Tesis de Licenciatura (orientación Arqueología), F. F. y L., UBA.

SPANO, R. 2011. Primera sistematización de las características estilísticas de la alfarería fina del sitio Soria 2 (Valle de Santa María, Noroeste argentino). Revista del Museo de Antropología 4: 127-144.

SPANO R., M. S. GRIMOLDI \& V. PALAMARCZUK. 2014 a. Morir temprano. Entierros de infantes en un espacio doméstico formativo de Santa María, noroeste argentino. Estudios. Antropología. Historia. Nueva serie 2: 141-173.
SPANO, R., M. S. GRIMOLDI, V. PALAMARCZUK \& A. ÁLVAREZ LARRAIN. 2014 b. Entre muros y vasijas: entierros y memoria en Soria 2, valle de Santa María. En: KORSTANJE, A., M. LAZZARI, M. BASILE, F. BUGLIANI, V. LEMA, L. PEREYRA DOMINGORENA \& M. QUESADA. Crónicas materiales precolombinas. Arqueología de los primeros poblados del noroeste argentino, pp. 485-517. SAA, Buenos Aires.

WINTON, A. L. \& K. B. WINTON. 1932. The structure and Composition of foods (Cereals, starch, oil seeds, nuts, oils, forage plants). New York.

WINTON, A. L. \& K. B. WINTON. 1935 The structure and composition of foods. John Willey y Sons, Inc. New York. 